\title{
Desafios na gestão escolar ${ }^{1}$
}

\section{Challenges in school administration \\ Desafios en la gestión escolar}

\section{FLÁVIA OBINO CORRÊA WERLE JANAINA FRANCISCATO AUDINO}

\begin{abstract}
Resumo: Este estudo discute a avaliação em larga escala da educação básica, os processos de regulação e debate processos de gestão realizados no interior da escola pública. Seu objetivo é compreender como a equipe diretiva de duas escolas da rede pública estadual de Porto Alegre, Brasil, se apropria dos resultados do Indíce de Desenvolvimento da Educação Básica (IDEB) e como lida com eles na gestão escolar. A metodologia utilizada é de cunho qualitativo com coleta de dados através de um questionário estruturado. Apresenta os resultados do IDEB das duas escolas no período de 2009 e 2011. Na prática escolar a apropriação ocorre em três dimensões (pedagógica, administrativa e participativa) e promove diálogos em diferentes níveis: com a hierarquia do sistema educacional, com a comunidade externa à escola e, internamente, com os professores e demais membros da comunidade escolar.
\end{abstract}

Palavras chave: Administração escolar; escola pública; avaliação em larga escala; Indice de Desenvolvimento da Educação; direção escolar.

Abstract: This study discusses the large scale evaluation of basic education, the regulation processes and debates administrative processes performed within public school. Their objective is to understand how the team that runs two schools of the state public network of Porto Alegre, Brasil, appropriates the results of the Index of Development of Basic Education (IDEB - Índice de Desenvolvimento da Educação Básica) and deal with them in school administration. The methodology used is qualitative, collecting data through a structured questionnaire. It presents the results of the IDEB of the two schools during the period of 2009 and 2011. In school practice the appropriation occurs in three dimensions (pedagogical, administrative and participatory) and promotes dialogues at different levels: with the hierarchy of the educational system, with the community outside the school and inside it with the teachers and other members of the school community.

Keywords: School administration; public school; large scale evaluation; Index of Development of Education; school directors.

\footnotetext{
${ }^{1}$ Este texto é um dos produtos do projeto Indicadores de qualidade e gestão democrática, vinculado ao Observatório de Educação INEP/CAPES. Os dados empíricos, trabalhados especialmente para este artigo, têm como fonte a dissertação do Mestrado Profissional em Gestão Educacional da Universidade do Vale do Rio dos Sinos, de Janaina Audino.
} 
Resumen: Esta investigación analiza la evaluación en gran escala de la educación básica, los procesos de regulación y los procesos de gestión en debate realizados en la escuela publica. Su objetivo es entender como el equipo de gestión de dos escuelas públicas de Porto Alegre, Brasil, se apropria de los resultados del Índice de Desarrollo de la Educación Basica (IDEB) y como tratar con ellos en la gestión escolar. La metodologia utilizada es un enfoque qualitativo para la recopilación de datos atraves de un cuestionario estructurado. IDEB presentan los resultados de dos escuelas a partir de 2009 y 2011. En la práctiva escolar la apropriación tendrá lugar en tres dimensiones(Pedagógico, administrativo y participativa) y promueve el dialogo en diferentes níveles: con la jerarquia del sistema educativo, con la comunidad externa a escuela y a nivel interno con los maestros y otros miembros de la comunidad escolar.

Palabras clave: Administración de la escuela; escuela pública; evaluación a gran escala; Indice de Desarrollo de la Educación, administración escolar.

\section{INTRODUÇÃO}

Objetiva-se com este texto discutir o contexto de prática, os micro movimentos de regulação local que se configuram a partir e por meio das formas como a equipe diretiva se posiciona e age frente ao Índice de Desenvolvimento da Educação Básica (IDEB). A pesquisa foi realizada em duas escolas de educação básica, estabelecimentos mantidos pelo poder público estadual, situados em Porto Alegre, focalizando ações da equipe diretiva para se apropriar dos dados do IDEB e para lidar com eles na gestão escolar. Discute-se inicialmente políticas públicas, avaliação em larga escala e processos de regulação para então apresentar os dados empíricos mediante a caracterização das escolas estudadas e a sistematização das formas de apropriação em níveis e dimensões.

\section{AVALIAÇÃO EM LARGA ESCALA COMO FORMA DE AÇÃO DO ESTADO}

Falar de avaliação em larga escala como política educacional é discutir uma face relevante dos processos de ação do Estado e suas formas de regulação. Os debates acerca do tema da regulação e da avaliação em larga escala da educação básica demonstram a amplitude e diversidade de sentidos com que o termo é empregado por pesquisadores bem como pelos que se situam no campo das práticas de escolas e sistemas.

A agenda das políticas públicas educacionais tem colocado cada vez mais ênfase na eficiência, eficácia, utilidade, administração de sistemas, e na gestão de organizações escolares. No cenário de globalização constituído por políticas de avaliação em larga escala, por processos de regulação e pelo destaque à gestão, 
encontram-se, na área da educação, posições divergentes. São posições que ora defendem a racionalização voltada para a eficácia, modernização e eficiência ou, ora priorizam a condição de liberdade dos atores, a autonomia das escolas e as possibilidades de uma gestão democrática da educação. O difícil, embora viável, é não abandonar o espaço de ação e profissionalismo dos atores que estão em diferentes espaços sociais, sistemas e instituições educativas e atender à urgência em oferecer uma educação pública de qualidade que inclua valores humanos de justiça, igualdade, tolerância (OLIVEIRA, ARAUJO, 2005; ESTEVÃO, 2004, 2008, 2009, 2011).

a globalização não supera as desigualdades nem as contradições, antes as recria, as desenvolve a outros níveis e com novos ingredientes e com novas linguagens (por exemplo, através de programas de ajustamento estrutural). Contudo, a solução não está tanto em saber se a globalização deve ou não ser rejeitada, "mas como pode ser regulada em termos de princípios que promovam a justiça social" (ESTEVÃO, 2009, p. 47).

O Estado manifesta-se através de sua ação (MULLER, SUREL, 2004; VIANA,1996), pela instituição de políticas públicas as quais são um alvo em movimento (PALUMBO, 1994), apresentando-se como tal, tanto para as instâncias político-administrativas e estruturas do Estado, como para os demais segmentos da sociedade. Assim, analisar o Estado é analisar a sua ação pública e suas lógicas de intervenção, identificando suas dinâmicas articulações com a sociedade.

Avaliações em larga escala da educação básica, como alvo em movimento e forma de manifestação do Estado, estão em operação no Brasil desde meados da década de 1990, adquirindo formas diferenciadas no tempo e, por constituírem um procedimento com tradição de quase vinte anos, veemse cada vez mais reforçadas e legitimadas no cenário atual. Constituem-se em políticas de continuidade das quais resultam e produzem-se grandes bases de dados. Entretanto, manejar com tais bases de dados implica em conhecimento técnico altamente especializado de forma que elas "não são exploradas em seu potencial, devido a dificuldades inerentes ao grande volume de dados envolvido, que inviabiliza a capacidade humana de sua interpretação" (NAMEN, BORGES, SADALA, 2013, p. 678).

Nos últimos anos como decorrência da robustez destas bases de dados e da permanência e reforçamento das políticas governamentais de avaliação em larga escala a educação brasileira tem sido representada por um índice que se torna cada vez mais reconhecido frente à sociedade - Índice de Desenvolvimento da Educação Básica. A legitimidade deste índice decorre da inserção do Brasil no movimento que institui "Estados avaliadores" (AFONSO, 2013; FREITAS, 
2009; ALMEIDA, 2013) e que é observado em diferentes países, na medida em que influências internacionais, favorecidas por processos de globalização, promovem a migração de políticas e a cultura de gestão por resultados, mediante a implantação de "sistemas de indicadores nacionais que lhes permitem 'dirigir" o sistema, 'controlar' melhor o processo e o funcionamento das escolas ou dos órgãos de gestão escolar de nível intermediário” (MAROY, VOISIN, 2013, p. 882). Tais indicadores, associados a mecanismos de prestação de contas (accountability), são utilizados como ferramenta de gestão, controle e planejamento dos sistemas educativos. Assim, se instalam políticas de regulação por resultados em que "a avaliação dos outputs dos sistemas organizacionais, referentes a objetivos e normas predeterminados, ocupa um lugar central" (MAROY, VOISIN, 2013, p. 883).

As políticas de avaliação em larga escala se inserem, portanto num cenário de regulação do Estado, regulação esta que pode, entretanto, ser entendida em diferentes níveis. A noção de regulação não é nova (MAROY, 2011); inicialmente conformada por um sentido funcionalista, passa por uma reconceituação frente às relações do Estado com a sociedade, os novos atores públicos, os processos de desconcentração, descentralização, parcerias e avaliações. A regulação institucional é exercida como propriedade ou função do sistema, do Estado, mediante leis e princípios hierárquicos (MAROY, 2011, p. 689); referese a "arranjos institucionais definidos, promovidos ou autorizados pelo Estado que contribuem para coordenar e orientar a ação do sistema educativo através da distribuição dos recursos e obrigações" (MAROY, VOISIN, 2014, p. 897). A regulação institucional reforça as dimensões de controle e influência de parte da autoridade formal ao induzir regulamentações e constrangimentos na ação social (BARROSO, 2004, p. 13).

Tal regulação que enfatiza regras decididas pela hierarquia, como propriedade do sistema, fomentada e associada a uma linha de gestão empresarial, instaura uma concepção de escola cujos objetivos são expressos em formato quantitativo, como padrões para redes escolares e níveis de ensino, tal como um "sistema de produção" no qual a escola precisa voltar-se prioritariamente para a melhoria de resultados. Assim as políticas de regulação governam por "números", indicadores, medidas quantificadas. Destaca-se, entretanto, que indicadores são um recurso metodológico necessário e importante para abordar realidades sociais podendo substituir, quantificar, operacionalizar aspectos complexos desta realidade (HADJI, 1994; FIGARI, 1996; JANNUZZI, 2009).

Outro enfoque para a noção de regulação volta-se para as possibilidades de exercício da liberdade e da reflexão humana, destacando que os sistemas de ação não se pautam exclusivamente pela sujeição e por constrangimentos, na linha que Barroso (2004 (a), p. 13; 2004 (b), p. 20), citando Bauby, explicita 
Modos de ajustamento permanentes de uma pluralidade de acções e seus efeitos que permitem assegurar o equilíbrio dinâmico de sistemas instáveis (...) A regulação resulta do facto de que as regras não podem prever tudo e por isso devem ser interpretadas, postas em causa (numa adaptação perpétua em função das situações e dos objectivos). A regulação de um grupo social corresponde, assim, às interacções entre os interesses particulares de cada componente do grupo e o interesse comum ou geral do mesmo.

Neste caso a regulação decorre de um processo ativo de produção de novas regras, de reajustamento de regras produzidas externamente, de consideração das condições específicas do contexto, dos múltiplos atores e das estratégias que eles adotam.

Maroy (2011, p. 689) destaca que a regulação, nesta perspectiva, é um "processo dinâmico, incompleto, portadora tanto de ordem quanto de novas tensões. (...) processo plural e conflituoso de produção de regras do jogo, com entrelaçamento de ações e dispositivos de coordenação, por natureza, situados e em contínua interação". E continua este autor, afirmando que há multiregulações locais, que a regulação é quase sempre múltipla, em decorrência da possibilidade de inter-relação entre controle e autonomia e das diversas fontes e forças que a originam. Conclusivamente afirma

Estamos numa situação de transição. Os novos modelos de regulação em desenvolvimento nos numerosos sistemas de ensino se conjugam e se articulam com modos de regulação anteriores, relativamente diversificados. Cada vez mais, os modelos pós-burocráticos mobilizam a regulação por resultados ou acionam dispositivos de quase-mercado, tendentes a se mesclar e retrabalhar fortemente as regulações anteriores, fundamentadas essencialmente na conformidade burocrática dos procedimentos e na autonomia profissional dos docentes (MAROY, 2011, p. 693)

Vários autores destacam o espaço de ação dos atores na dinâmica social. Certeau (2011, p. 37 ss) acentua que as pessoas comuns não são entregues à passividade e à disciplina, suas práticas (de apropriação, de reapropriação, de subversão, de consumo, de recepção, as micro resistências, as inércias) são uma equivalente às regras e imposições externas, de forma que, ao mesmo tempo, uma ordem é exercida e burlada. Licinio Lima (2001, p.62 ss) reconhece a complexidade dos processos que ocorrem entre a concepção normativa das políticas e sua execução em espaços escolares. Ele fala em infidelidade normativa, em uma certa invulnerabilidade dos professores a regras, a procedimentos burocráticos e imposições. Tanto Certeau como Lima nos textos que refiro não tratam, explicitamente, de regulação, mas apresentam uma concepção próxima de "processo ativo de produção de regras do jogo", citado por Barroso (2004, p. 14). 
Ou seja, as formas de praticar, a capacidade dos atores escolares para ignorar ou redefinir regras e a possibilidade de, em grupo ou individualmente, fazer uso estratégico dos processos de interação e do espaço de interpretação de normas que não produziram, colabora para o alargamento da ideia de regulação.

Assim como Estado, políticas públicas e regulação, a avaliação é também um tema muito debatido. Vale referir aqui as diversas gerações de avaliação (GUBA, LINCOLN, 2011) e lembrar que elas não são necessariamente sucessivas mas podem estar em operação, concomitantemente. A primeira geração caracteriza-se pela ênfase na mensuração, nos testes. Nela o avaliador desempenha função eminentemente técnica pois precisa "conhecer o arsenal de instrumentos disponíveis para que, deste modo, qualquer variável que se desejasse investigar pudesse ser mensurada. Se não houvesse nenhum instrumento apropriado, supunha-se que o avaliador tivesse o conhecimento necessário para criá-lo" (GUBA, LINCOLN, 2011, p. 33). Já a segunda geração caracteriza-se "pela descrição de padrões de pontos fortes e fracos com respeito a determinados objetivos estabelecidos. O avaliador cumpria a função de descritor, embora também se mantivessem os aspectos técnicos anteriores dessa função. A mensuração então deixou de ser tratada como equivalente à avaliação ...” (GUBA, LINCOLN, 2011, p. 35). Quando “a avaliação se caracterizou por iniciativas que visavam alcançar juízos de valor e na qual o avaliador assumiu o papel de julgador, mantendo igualmente as funções técnicas e descritivas anteriores" (GUBA, LINCOLN, 2011, p. 37), chegou-se então á terceira geração de avaliação.

A quarta, geração de avaliação, entretanto, diferencia-se das anteriores gerações por enfatizar a negociação, por ser uma proposta participativa desde as fases iniciais do processo em que avaliador e avaliados não estão em campos opostos, mas em paridade e compartilhando a avaliação em suas diferentes fases como uma construção conjunta. Pode-se afirmar que as avaliações em larga escala no Brasil (como a Prova Brasil e indicadores dela consequentes) não adotam a proposta da quarta geração. Pode-se entretanto dizer que as avaliações de quarta geração são mais coerentes com o quadro teórico que compreende as políticas como um alvo em movimento, a regulação como interação, que percebe a existência de multiregulações locais, que sabem que as normas burocráticas, as regras e padrões não prevêem tudo e, portanto, estão em adaptação e interpretação perpétuas.

Como destacado anteriormente, estas quatro "gerações de avaliação" coexistem, convivem atualmente nas relações sociais. Assim, na área de educação e considerando a educação básica há muitas queixas em relação à utilização dos dados das avaliações em larga escala, o que ocorre também em outros países. 
Guba e Lincoln (2011, p. 16) afirmam com relação aos profissionais da área de avaliação que eles estão "chocados com a não utilização da avaliação, ora culpam os clientes pelo capricho obstinado em não agir, não obstante a lógica convincente das recomendações, ora se culpam por não 'promover' satisfatoriamente o produto da avaliação".

O objetivo deste texto é discutir justamente os processos de apropriação destes resultados mediante a ação do gestor escolar. $O$ foco da pesquisa é o contexto de prática, onde os atores reconfiguram as regras do jogo, na linha de micro-regulação local mediante a qual poderá ocorrer a produção de regras e de quadros de referência por processos de apropriação que sempre são únicos, localizados e contingentes. Embora o cenário mais amplo aponte para o nascimento de uma lógica voltada para a eficiência e a eficácia, em que os objetivos são definidos mediante indicadores quantificados, a pesquisa investiga como as equipes diretivas se movimentam buscando dar sentido a um indicador de abrangência nacional criado externamente, que se apresenta como capaz de expressar o desenvolvimento da educação em sua escola. A pesquisa, portanto, focaliza processos de gestão desencadeados pelas equipes diretivas de escolas públicas de educação básica.

Como já foi dito, o Estado Avaliador, sendo uma alternativa ao Estado Burocrático e centralizado, ao agir diferentemente daquele, passa a definir os comportamentos esperados, os resultados, enfatizando métricas. O Estado Avaliador, ao priorizar resultados quantitativos, delega a gestão dos meios e processos às instâncias periféricas e descentralizadas (departamentos, municipalidades, instituições), não dando conta, portanto, dos fenômenos que contribuem para uma regulação das ações no âmbito das escolas.

Maroy e Dupriez (2000, p. 74), assumem que a regulação é um processo de produção de regras e orientações de conduta. Regras que são apreendidas em sentido amplo, seja como injunção ou como interdição de comportamentos. Regras que podem atuar, também, como um guia de ação, uma referência que permita formular julgamentos ou um modelo que oriente a ação. Ou seja, a regulação pode ser entendida como a capacidade de regular interações. Voltando à proposta desta pesquisa pretende-se descrever de que forma ocorre a apropriação ou a capacidade de regular interações por parte da equipe diretiva de duas escolas públicas de Porto Alegre.

\section{O ESPAÇO EMPÍRICO: CARACTERIZANDO AS ESCOLAS}

A pesquisa envolve duas escolas públicas da zona urbana de Porto Alegre, localizadas em bairros distintos. A abordagem qualitativa caracteriza-se pelo 
interesse em termos do processo da gestão escolar mais do que simplesmente pelo resultado do IDEB. Tem como estratégia de coleta de dados, um questionário estruturado, com dez perguntas abertas e a análise de documentos que informam acerca do funcionamento das escolas, como o Projeto Político Pedagógico (PPP) e o Regimento escolar (AUDINO, 2014).

Faz-se necessário esclarecer que não há a intenção de fazer uma análise comparativa entre as duas escolas, pois, com o apoio da fundamentação teórica, entende-se que cada escola expressa através de seus profissionais, valores, vontades, contextos específicos (embora não opostos) e respostas diferentes. Ao contrário, nesta pesquisa, embora a caracterização de cada instituição destaque suas condições específicas, a análise da gestão é realizada num todo, objetivando destacar as estratégias de gestão adotadas que ora podem ser específicas, mas que, na maioria das vezes, são convergentes entre as duas escolas.

O público alvo é a equipe diretiva, representada pelo diretor(a), vicediretores, coordenação ou supervisão pedagógica e a orientação educacional. Nas duas escolas, o questionário foi respondido de forma presencial por todos integrantes da equipe diretiva em datas específicas agendadas pelas diretoras, no início de 2014. Com autorização das escolas manteve-se sua designação original.

A Escola Estadual de Ensino Fundamental Monsenhor Roberto Landell de Moura, situa-se na Zona Sul de Porto Alegre/RS. É bem localizada no bairro, com acesso a transporte público, de rotas e horários diversificados. No mesmo zoneamento funcionam outras três escolas públicas estaduais de ensino fundamental.

A escola foi criada pelo Decreto no 8.609, de 11 de fevereiro de 1958, com a denominação de Grupo Escolar, à Rua José Gomes. Nos anos seguintes, com a implantação da $5^{\text {a }}$ série e, gradativamente, das séries subsequentes, a escola foi reconhecida pela Portaria de $n^{\circ} 20.120$, de 07 de agosto de 1987, como Escola Estadual de $1^{\circ}$ Grau Monsenhor Roberto Landell de Moura. Atualmente, conta com 28 professores e 7 funcionários para atender 456 alunos matriculados nos turnos manhã e tarde.

A Escola Estadual de Ensino Fundamental Major Miguel José Pereira, está localizada na Vila Elizabeth, Zona Norte de Porto Alegre/RS, considerada uma área urbana em região periférica. No mesmo bairro, estão localizadas outras cinco instituições de ensino. $\mathrm{O}$ acesso utilizando-se de transporte público é limitado, sendo que a parada de ônibus mais próxima fica a uma quadra da escola, com apenas uma linha de lotação.

Foi criada em 30 de agosto de 1958, pelo Decreto Estadual no 9.327 que a denominou como Grupo Escolar Major Miguel José Pereira. Em 2003, a escola iniciou o atendimento da $6^{a}$ série do ensino fundamental e, em 2010, das $7^{\mathrm{a}}$ e 
$8^{a}$ séries. Conta com 26 professores e 6 funcionários para atender 452 alunos matriculados nos turnos manhã e tarde.

\section{O QUE DIZ O IDEB DAS ESCOLAS DA PESQUISA}

A análise das taxas de aprovação da Escola Estadual de Ensino Fundamental Monsenhor Roberto Landell de Moura, indica que ela atingiu seu melhor percentual de aprovação em 2010. Entretanto, registrou-se, em 2010, um decréscimo significativo nesta taxa de aprovação do ensino fundamental II, a qual foi em parte recuperada em 2011.

\section{Quadro 1 - Histórico da Taxa de aprovação, por nível de ensino: EEEF Monsenhor Roberto Landell de Moura}

\begin{tabular}{|c|c|c|c|}
\hline ETAPA DE ENSINO & $\mathbf{2 0 1 0}$ & $\mathbf{2 0 1 1}$ & $\mathbf{2 0 1 2}$ \\
\hline EFI & $91 \%$ & $88 \%$ & $89 \%$ \\
\hline EFII & $69 \%$ & $54 \%$ & $58 \%$ \\
\hline
\end{tabular}

Fonte: MEC/INEP

Verifica-se que esta escola tem conseguido aprovar seus alunos no ensino fundamental I, mas apresenta um grande desafio a ser enfrentado: $42 \%$ de reprovação no ensino fundamental II, em 2012.

Em relação à Prova Brasil de Língua Portuguesa no ensino fundamental I, observa-se uma oscilação nas médias, alcançando o melhor resultado na avaliação de 2009. No ensino fundamental II, na disciplina de Língua Portuguesa, constatase um crescimento na avaliação de 2007 se comparada a 2005, seguida de um decréscimo no comparativo de 2009 com 2007, crescendo significativamente em 2011, edição em que a escola alcançou a sua melhor média. Na disciplina de Matemática, as médias tanto no ensino fundamental I e II, oscilam bastante de um ano para outro, apresentando a melhor média no ensino fundamental I na avaliação de 2009 e, a melhor média no ensino fundamental II, no ano de 2011. 


\section{Quadro 2 - Histórico da Prova Brasil por nível de ensino e área de}

conhecimento EEEF Monsenhor Roberto Landell de Moura

\begin{tabular}{|l|c|c|c|c|c|c|c|c|}
\hline ANO & \multicolumn{2}{|c|}{2005} & \multicolumn{2}{c|}{2007} & \multicolumn{2}{c|}{2009} & \multicolumn{2}{c|}{2011} \\
\hline DISC. & PORT & MAT & PORT & MAT & PORT & MAT & PORT & MAT \\
\hline EFI & 197,37 & 242,76 & 194,27 & 209,19 & 215,79 & 266,75 & 207,00 & 218,20 \\
\hline EFII & 204,34 & 241,20 & 259,57 & 259,02 & 234,32 & 266,25 & 276,30 & 287,62 \\
\hline
\end{tabular}

Fonte: MEC/INEP

A escala da Prova Brasil está organizada por área de conhecimento: Língua Portuguesa com 10 níveis e Matemática com 13 níveis, por etapa avaliada. Em Língua Portuguesa, a média da escola de 207,00 no $5^{\circ}$ ano, na edição que ocorreu em 2011, refere-se ao nível 4 (200 a 225) e no $9^{\circ}$ ano, a média de 276,30, ao nível 7 (275 a 300). As médias em Matemática no $5^{\circ}$ ano $(218,20)$ e $9^{\circ}$ ano $(287,62)$, correspondem aos níveis 4 e 7 , respectivamente.

Assim, no IDEB do ensino fundamental I, a escola teve um crescimento de 10 pontos na edição de 2011 em relação a 2005 e, no ensino fundamental II, de 6 pontos, sendo que seu melhor resultado foi em 2007.

\section{Quadro 3 - Histórico do IDEB por nível de ensino - EEEF Monsenhor Roberto Landell de Moura}

\begin{tabular}{|c|c|c|c|c|}
\hline ETAPA & $\mathbf{2 0 0 5}$ & $\mathbf{2 0 0 7}$ & $\mathbf{2 0 0 9}$ & $\mathbf{2 0 1 1}$ \\
\hline EFI & 4,2 & 4,7 & 5,3 & 5,2 \\
\hline EFII & 2,5 & 3,4 & 2,9 & 3,1 \\
\hline
\end{tabular}

Fonte: MEC/INEP

A Escola Estadual de Ensino Fundamental Major Miguel José Pereira não tem resultado no IDEB do ensino fundamental I na edição de 2011, devido à exigência do número de alunos e, seu primeiro resultado no ensino fundamental II foi registrado em 2011, devido a recente autorização de funcionamento da $8^{\circ}$ série, em 2010. 


\section{Quadro 4 - Histórico do IDEB por nível de ensino: \\ EEEF Major Miguel José Pereira}

\begin{tabular}{|c|c|c|c|c|}
\hline ETAPA & $\mathbf{2 0 0 5}$ & $\mathbf{2 0 0 7}$ & $\mathbf{2 0 0 9}$ & $\mathbf{2 0 1 1}$ \\
\hline EFI & 4,6 & 4,8 & 5,1 & $* * *$ \\
\hline EFII & $*$ & $*$ & $*$ & 4,4 \\
\hline
\end{tabular}

Fonte: MEC/INEP

Ao se analisar as taxas de aprovação observa-se que a escola vem aprovando o mesmo percentual de alunos no ensino fundamental I, desde 2010. No ensino fundamental II, observa-se um crescimento modesto em 2012, em relação ao ano letivo de 2011.

Quadro 5 - Histórico da Taxa de aprovação, por nível de ensino: EEEF Major Miguel José Pereira

\begin{tabular}{|c|c|c|c|}
\hline ETAPA DE ENSINO & $\mathbf{2 0 1 0}$ & $\mathbf{2 0 1 1}$ & $\mathbf{2 0 1 2}$ \\
\hline EFI & $92,6 \%$ & $93 \%$ & $93,8 \%$ \\
\hline EFII & $*$ & $71,7 \%$ & $73,5 \%$ \\
\hline
\end{tabular}

Fonte: MEC/INEP

Na última edição da Prova Brasil, em 2011, a escola procedeu com a avaliação apenas para os alunos do $9^{\circ}$ ano ( $8^{a}$ série). Em Língua Portuguesa, a média da escola de 276,60 refere-se ao no nível 7 (275 a 300) e a média de matemática 273,80 ao nível 6 (250 a 275).

Quadro 6 - Histórico da Prova Brasil por nível e área de conhecimento EEEF Major Miguel José Pereira

\begin{tabular}{|l|l|l|l|l|l|l|l|l|}
\hline ANO & \multicolumn{2}{|c|}{2005} & \multicolumn{2}{c|}{2007} & \multicolumn{2}{c|}{2009} & \multicolumn{2}{c|}{2011} \\
\hline DISC. & PORT & MAT & PORT & MAT & PORT & MAT & PORT & MAT \\
\hline EFI & 193,23 & 203,01 & 184,79 & $*$ & 202,40 & 216,62 & $*$ & $*$ \\
\hline EFII & $*$ & $*$ & 202,28 & $*$ & $*$ & $*$ & 276,60 & 273,80 \\
\hline
\end{tabular}

Fonte: MEC/INEP

Nesta escola, no ensino fundamental II, o resultado do IDEB de 4,4 em 2011, tem um peso positivo pela taxa de aprovação em 73,5\%, combinada com as médias da Prova Brasil em Português e Matemática, 276,60 e 273,80, respectivamente. 


\section{O ESPAÇO EMPÍRICO: MOVIMENTOS DE APROPRIAÇÃO DO IDEB PELAS EQUIPES DIRETIVAS}

Na sequência, apresenta-se a análise dos dados, tratando as informações em conjunto, sem diferenciar escola nem informantes. O que interessa aqui é apreender os movimentos do conjunto dos componentes da equipe diretiva e as formas de apropriação deste conjunto em relação aos resultados do IDEB a partir de três níveis de diálogo. Analisando-se os dados coletados e com inspiração na literatura consultada (WERLE, 2010) organizou-se a sistematização em três níveis de diálogo.

O primeiro nível refere-se à percepção das equipes diretivas em relação à postura da Secretaria de Estado da Educação, quanto à devolutiva dos resultados do IDEB às escolas. No segundo, aos processos internos da gestão escolar. O terceiro situa-se no nível do diálogo extraescolar, articulando formas de comunicação com os diferentes segmentos: família, alunos e conselhos.

Para cada nível de diálogo, as diferentes formas de compreensão e manejo dos resultados do IDEB, descritas pelas equipes diretivas das escolas, identificouse dimensões consideradas como fundamentais para o desenvolvimento dos processos de gestão.

A dimensão Pedagógica abrange as práticas do trabalho educativo voltadas para assegurar a aprendizagem dos alunos. Relaciona-se à forma como a equipe diretiva interage, percebe e articula a sua ação, especialmente, junto ao corpo docente. A dimensão administrativa inclui formas de organização e estratégias reflexivas voltadas para o domínio dos dados do IDEB e o relacionamento dos dados (pistas) que ele fornece com o percurso histórico da instituição e demais informações produzidas pelos atores escolares. Na dimensão participativa destacamse os esforços de articulação de indivíduos e grupos, assim como as iniciativas de interação voltadas para disseminar o tema do IDEB e da importância da aprendizagem do estudante junto a todos da comunidade escolar.

Tais dimensões perpassam de forma diferenciada os níveis em que ocorrem os diálogos das equipes diretivas, níveis estes que se referem à hierarquia do sistema de ensino, ao interior da escola e à comunidade próxima.

No primeiro nível, dialogando com a bierarquia da Secretaria do Estado de Educação do Rio Grande do Sul, identificou-se que as equipes diretivas não descrevem uma interação pedagógica e participativa em relação aos resultados do IDEB, com o que, as colunas da direita e da esquerda no quadro 7, estão em branco. Nas duas escolas os resultados são recebidos pelo correio, sendo que uma escola diz receber informações sobre a divulgação do IDEB da Coordenadoria Regional de Educação (CRE) que é o órgão de ligação e representação da Secretaria Estadual 
de Educação junto às escolas que são organizadas regionalmente. A relação com a hierarquia do sistema demonstra que a escola precisa encontrar sentido no IDEB por seus próprios meios e estratégias. É uma relação que demonstra certa inércia, mediante a utilização de mecanismos que indicam distanciamento para com as escolas e uma forma burocrática de relacionamento.

\section{Quadro 7- Nível 1: Dialogando com a hierarquia do Sistema Educacional, movimentos de apropriação do IDEB pelas equipes diretivas nas dimensões: pedagógica, administrativa e participativa}

\begin{tabular}{|c|c|c|}
\hline \multicolumn{2}{|c|}{ Nível 1- Dialogando com a hierarquia do Sistema Educacional } \\
\hline Pedagógica & Administrativa & Participativa \\
\hline & Buscam os dados no site do MEC & \\
\hline & Recebem informações via CRE/SE e pelo correio & \\
\hline
\end{tabular}

Fonte: Dados coletados mediante questionário aplicado na pesquisa.

Em nível de diálogo interno (quadro 8) identifica-se uma ênfase entre os movimentos de apropriação nas dimensões administrativa e pedagógica. Isso evidencia a proposta de um trabalho preventivo que visa identificar as defasagens dos alunos, conforme citado nos documentos legais que regem o funcionamento das escolas.

$\mathrm{Na}$ dimensão pedagógica, ressalta-se a discussão dos resultados do IDEB entre os gestores e professores, o que, pelo levantamento da produção acadêmica da área é recomendável, mas a literatura informa que nem sempre é praticado nas redes de ensino. Assim, considera-se que nestas escolas há um avanço na maturidade gerencial em relação à análise dos resultados, pela diversidade de alternativas adotadas.

Ainda na dimensão pedagógica, observa-se que as equipes diretivas proporcionam aos professores, formações específicas de atualização, estando abertas para novas metodologias de ensino. Além da troca de experiências, do reforço escolar e do planejamento em conjunto, estas equipes apresentam um olhar favorável à Prova Brasil. Tal aceitação da avaliação externa pode contribuir não só para o trabalho compartilhado frente a objetivos comuns, mas para a elevação da aprendizagem e permanência dos alunos na escola além de trazer interferências positivas para os resultados futuros do IDEB. O trabalho pedagógico desenvolvido nas escolas indica uma postura ativa que possibilita mapear as habilidades e competências a serem trabalhas com os alunos em cada etapa de ensino. 
$\mathrm{Na}$ dimensão administrativa percebe-se que grande parte dos esforços endereçam-se para uma gestão voltada para resultados, pautada no trabalho coletivo dos profissionais. Quanto à dimensão participativa, é possível identificar uma gestão atenta aos comportamentos e necessidades dos alunos e às solicitações dos professores. A gestão é dinâmica, buscando formas diferenciadas de comunicação e de agilização dos encaminhamentos propostos. Destaca-se, também, movimentos de socialização dos resultados do IDEB com todos os segmentos, abrindo espaços para um planejamento em conjunto, abrindo espaços para diálogos e questionamentos.

As diferentes formas de apropriação em nível de diálogo interno, indicam que os resultados do IDEB são considerados para o alinhamento da proposta pedagógica das escolas, estando este processo aberto para reformulações, para atender as expectativas de aprendizagens apontadas pelo corpo docente, as famílias e os alunos. Verifica-se também que tal apropriação se manifesta mediante estratégias de envolvimento de todos os segmentos da comunidade escolar (professores, pais, alunos, equipe diretiva, funcionários) e uma ênfase em buscar alternativas que reúnam os esforços coletivos. Neste sentido as reuniões se constituem em momentos de articulação e revisitação de dados históricos relativos à aprendizagem dos alunos, de discussão de diferentes metodologias de trabalho, de compartilhamento de conhecimento tácito acumulado no fazer pedagógico diário dos professores e equipe diretiva. Destaca-se também a importância da equipe diretiva considerar, igualmente, dados das avaliações em larga escala, bem como dados e indicadores oriundos de outros recursos disponíveis para a escola e os produzidos pelos professores, demonstrando assim, interesse e valorização de dados produzidos em diferentes origens.

\section{Quadro 8 - Nível 2: Dialogando internamente: movimentos de apropriação do IDEB pelas equipes diretivas nas dimensões: pedagógica, administrativa e participativa}

\begin{tabular}{|l|l|l|}
\hline \multicolumn{2}{|c|}{ Nível 2- Dialogando internamente: equipe diretiva } \\
\hline \multicolumn{1}{|c|}{ Pedagógica } & \multicolumn{1}{|c|}{ Administrativa } & \multicolumn{1}{c|}{ Participativa } \\
\hline $\begin{array}{l}\text { Discutem os resultados nas } \\
\text { reuniões com os professores }\end{array}$ & $\begin{array}{l}\text { Analisam os resultados } \\
\text { e discutem em reuniões } \\
\text { específicas de equipe }\end{array}$ & $\begin{array}{l}\text { Socializam os } \\
\text { resultados com os pais } \\
\text { e alunos }\end{array}$ \\
\hline $\begin{array}{l}\text { Utilizam o indicador } \\
\text { para repensar as práticas } \\
\text { pedagógicas }\end{array}$ & $\begin{array}{l}\text { Priorizam reuniões } \\
\text { semanais de equipe } \\
\text { diretiva }\end{array}$ & $\begin{array}{l}\text { Discutem os } \\
\text { resultados com os pais } \\
\text { e alunos }\end{array}$ \\
\hline
\end{tabular}




\begin{tabular}{|c|c|c|}
\hline \multicolumn{3}{|c|}{ Nível 2- Dialogando internamente: equipe diretiva } \\
\hline Pedagógica & Administrativa & Participativa \\
\hline $\begin{array}{l}\text { Identificam o que precisa ser } \\
\text { melhorado no processo de } \\
\text { ensino } \\
\text { e aprendizagem }\end{array}$ & $\begin{array}{l}\text { Comparam o IDEB com } \\
\text { os resultados produzidos } \\
\text { na própria escola }\end{array}$ & $\begin{array}{l}\text { Discutem os resultados } \\
\text { no Conselho de Classe } \\
\text { participativo }\end{array}$ \\
\hline $\begin{array}{l}\text { Adotam formas diferentes de } \\
\text { trabalhar na sala de aula }\end{array}$ & $\begin{array}{l}\text { Analisam e comparam } \\
\text { os resultados com os } \\
\text { anos anteriores - outras } \\
\text { escolas -regiões }\end{array}$ & $\begin{array}{l}\text { Envolvem a } \\
\text { comunidade escolar } \\
\text { nas discussões de } \\
\text { alternativas: Como? } \\
\text { Com quem? Para } \\
\text { quem? }\end{array}$ \\
\hline $\begin{array}{l}\text { Identificam as dificuldades de } \\
\text { aprendizagens dos alunos }\end{array}$ & $\begin{array}{l}\text { Utilizam o IDEB como } \\
\text { norteador do trabalho, } \\
\text { serve como parâmetro } \\
\text { para novos projetos }\end{array}$ & $\begin{array}{l}\text { Socializam as boas } \\
\text { práticas nas reuniões } \\
\text { com a comunidade } \\
\text { escolar }\end{array}$ \\
\hline $\begin{array}{l}\text { Analisam os resultados } \\
\text { internos da escola por ano/ } \\
\text { turmas }\end{array}$ & $\begin{array}{l}\text { Utilizam gráficos para } \\
\text { apresentar os resultados à } \\
\text { comunidade escolar }\end{array}$ & $\begin{array}{l}\text { Incentivam a } \\
\text { participação dos } \\
\text { alunos no processo de } \\
\text { aprendizagem }\end{array}$ \\
\hline $\begin{array}{l}\text { Planejam atividades para } \\
\text { melhorar o desempenho dos } \\
\text { alunos }\end{array}$ & $\begin{array}{l}\text { Identificam as causas e } \\
\text { não culpados }\end{array}$ & $\begin{array}{l}\text { Chamam os pais para } \\
\text { conversas individuais }\end{array}$ \\
\hline $\begin{array}{l}\text { Realizam aulas de reforço } \\
\text { escolar em horários diferentes }\end{array}$ & $\begin{array}{l}\text { Discutem a reformulação } \\
\text { dos documentos } \\
\text { norteadores }\end{array}$ & \\
\hline $\begin{array}{l}\text { Estabelecem projetos a partir } \\
\text { da necessidade dos alunos }\end{array}$ & $\begin{array}{l}\text { Analisam os resultados } \\
\text { produzidos na escola em } \\
\text { cada trimestre }\end{array}$ & \\
\hline $\begin{array}{l}\text { Realizam momentos de troca } \\
\text { de experiências de aulas que } \\
\text { tiveram efetiva participação } \\
\text { dos alunos }\end{array}$ & $\begin{array}{l}\text { Acompanham os } \\
\text { resultados trimestrais } \\
\text { através do sistema } \\
\text { gerencial }\left(\mathrm{GIDE}^{1}\right)\end{array}$ & \\
\hline
\end{tabular}

\footnotetext{
${ }^{1}$ Sistema de gestão integrada da escola idealizado pela professora Maria Helena de Pádua Coelho de Godoy, coordenadora dos Projetos de Gestão na Área da Educação na Fundação de Desenvolvimento Gerencial e Consultora Master do Instituto Aquila.
} 
O diálogo com a comunidade escolar (quadro 9) envolve interações com as famílias e os alunos no processo de acompanhamento das atividades escolares. O esforço volta-se não apenas para o conhecimento e a análise dos resultados do IDEB, mas para os avanços no desempenho geral dos alunos, expressando uma atitude efetiva (ouvir e valorizar), uma vez que as famílias destas escolas cobram um ensino de qualidade. A prática de convidar e motivar os responsáveis e os alunos a discutir sobre a frequência dos estudantes às aulas, seu aproveitamento e o IDEB estimula as equipes a acompanhar em profundidade a dinâmica pedagógica e as metodologias em desenvolvimento bem como os resultados e as formas para melhorá-los. Observa-se que as equipes diretivas destas escolas envolvem, pois valorizam o Conselho Escolar e todos os segmentos da comunidade escolar na discussão de alternativas, assim como na divulgação e acompanhamento de ações administrativas, culturais, pedagógicas promovidas, diversificando as modalidades de comunicação da escola com os pais.

\section{Quadro 9 - Nível 3: Dialogando com a comunidade escolar, movimentos de apropriação do IDEB pelas equipes diretivas nas dimensões: pedagógica, administrativa e participativa}

\begin{tabular}{|l|l|l|}
\hline \multicolumn{2}{|c|}{ Nível 3 - Dialogando com a comunidade escolar } \\
\hline \multicolumn{1}{|c|}{ Pedagógica } & \multicolumn{1}{|c|}{ Administrativa } & \multicolumn{1}{c|}{ Participativa } \\
\hline $\begin{array}{l}\text { Realizam reuniões } \\
\text { individuais com as turmas } \\
\text { (alunos e pais) para } \\
\text { sanar dificuldades de } \\
\text { aprendizagem }\end{array}$ & $\begin{array}{l}\text { Agendam horários } \\
\text { diferenciados para } \\
\text { atender os pais }\end{array}$ & $\begin{array}{l}\text { Socializam os resultados } \\
\text { com o Conselho Escolar }\end{array}$ \\
\hline $\begin{array}{l}\text { Promovem discussões } \\
\text { para sanar ou minimizar os } \\
\text { problemas de aprendizagem }\end{array}$ & $\begin{array}{l}\text { Divulgam os resultados } \\
\text { do IDEB em áreas } \\
\text { visíveis da escola }\end{array}$ & $\begin{array}{l}\text { Socializam os resultados } \\
\text { com as famílias e com os } \\
\text { alunos }\end{array}$ \\
\hline $\begin{array}{l}\text { Envolvem o Conselho } \\
\text { Escolar no planejamento } \\
\text { das atividades pedagógicas }\end{array}$ & $\begin{array}{l}\text { Buscam socializar com } \\
\text { todo o segmento escolar } \\
\text { os resultados do IDEB }\end{array}$ & $\begin{array}{l}\text { Discutem os resultados } \\
\text { com } \\
\text { todos os segmentos }\end{array}$ \\
\hline $\begin{array}{l}\text { Envolvem os alunos no } \\
\text { processo de aprendizagem }\end{array}$ & $\begin{array}{l}\text { Criam estratégias } \\
\text { de divulgação dos } \\
\text { resultados, como gráfico } \\
\text { e tabelas }\end{array}$ & $\begin{array}{l}\text { Promovem eventos } \\
\text { tradicionais na escola }\end{array}$ \\
\hline
\end{tabular}




\begin{tabular}{|c|c|c|}
\hline \multicolumn{3}{|c|}{ Nível 3 - Dialogando com a comunidade escolar } \\
\hline Pedagógica & Administrativa & Participativa \\
\hline \multirow[t]{4}{*}{$\begin{array}{l}\text { Buscam os serviços de } \\
\text { apoio } \\
\text { (rede de atendimento) } \\
\text { para os alunos }\end{array}$} & $\begin{array}{l}\text { Monitoram as ações } \\
\text { realizadas } \\
\text { na escola }\end{array}$ & $\begin{array}{l}\text { Discutem no coletivo } \\
\text { as alternativas para } \\
\text { minimizar } \\
\text { os problemas }\end{array}$ \\
\hline & $\begin{array}{l}\text { Conversam, cobram e } \\
\text { envolvem } \\
\text { a comunidade escolar } \\
\text { nas decisões }\end{array}$ & $\begin{array}{l}\text { Relatam para os pais o } \\
\text { desenvolvimento dos } \\
\text { alunos }\end{array}$ \\
\hline & $\begin{array}{l}\text { Acolhem as diferentes } \\
\text { ideias dos pais, } \\
\text { funcionário e alunos }\end{array}$ & $\begin{array}{l}\text { Trabalham com os alunos } \\
\text { o seu desempenho }\end{array}$ \\
\hline & $\begin{array}{l}\text { Proporcionam } \\
\text { momentos de escuta } \\
\text { para os diferentes } \\
\text { públicos }\end{array}$ & \\
\hline
\end{tabular}

Fonte: Dados coletados mediante questionário aplicado pela autora.

\section{CONCLUSÕES}

Neste estudo, o IDEB foi considerado como um índice positivo pelas duas equipes diretivas que afirmam que a proposta pedagógica está sendo reformulada a fim de melhorar a qualidade da educação, refletida na aprendizagem dos alunos. Há uma compreensão de parte das equipes diretivas a respeito da importância da aprendizagem significativa de todos os estudantes, das condições de aprovação e promoção ao longo do ensino fundamental, do papel do professor e de toda a comunidade escolar para o sucesso do trabalho educativo.

O que se pode concluir é que as avaliações externas estabelecem parâmetros que não podem ser considerados em si mesmos e nem como sinal da qualidade da escola, mas cabe aos sistemas de ensino e suas respectivas escolas se debruçarem nos resultados do IDEB a fim de diagnosticar a situação de aprendizagem de seus alunos. Ou seja, a qualidade da educação não pode ficar restrita ao índice, mas ele pode ser um bom instrumento para apontar alguns caminhos interessantes na gestão escolar. Frente ao IDEB as equipes diretivas 
das escolas pesquisadas demonstram grande esforço reflexivo, de entendimento de forma a articular outros dados e elementos chave da escola: formação continuada dos professores, metodologia de ensino e, até mesmo, mudanças na base curricular das escolas.

As duas escolas estudadas caminham neste sentido e consideram os resultados do IDEB no planejamento das estratégias, através de diferentes movimentos de apropriação, o que leva a reforçar a ideia de que a qualidade da educação começa dentro da escola, com a introdução de boas práticas de gestão.

Os dados coletados sugerem que as equipes diretivas reconhecem o direito dos pais, dos professores, dos alunos e dos funcionários e corpo técnico administrativo ao diálogo, à contestação e à pergunta. Sugerem também que as equipes diretivas dão expressão a princípios democráticos nas ações administrativas, pedagógicas e de articulação com a comunidade.

As escolas que foram objeto de estudo afiguram-se como espaços de construção de formas peculiares de regulação ao demonstrarem estar atentas ao IDEB, mas deixando-se atravessar por compromisso, solidariedade e trabalho conjunto.

\section{REFERÊNCIAS}

AFONSO, Almerindo Janela. Mudanças no Estado-avaliador: comparativismo internacional e teoria da modernização revisitada. Revista Brasileira de Educação, v. 18, n. 53, p. 267 - 284, abr/jun. 2013. Disponivel: http://www. scielo.br/pdf/rbedu/v18n53/02.pdf Acesso: 10/12/2013.

ALMEIDA, Maria de Lourdes Pinto de. Políticas de educação e Estado Avaliador na América Latina: uma análise para além das avaliações externas. REICE. Revista Iberoamericana sobre Calidad, Eficacia y Cambio en Educación, v.11, n.4, p.77-91, 2013.

AUDINO, Janaina. Movimentos de apropriação do IDEB na gestão escolar em duas escolas da rede pública estadual de Porto Alegre/RS. São Leopoldo: Unisinos, 2014. Universidade do Vale do Rio dos Sinos, Programa de Pós-Graduação em Gestão Educacional, Dissertação de Mestrado Profissional.

BARROSO, João Novos modos de regulação das políticas educativas na Europa: da regulação de sistema a um sistema de regulações. Educação em Revista, Belo Horizonte, v. 39, p. 19 - 28, jul. 2004. (b) 
BARROSO, João. A regulação da educação como processo compósito: tendências e desafios. In: COSTA, Jorge Adelino, MENDES-NETO, António, VENTURA, Alexandre. Políticas e gestão local da educação. Actas do III Simpósio sobre organização e gestão escolar. Aveiro, PT: Universidade de Aveiro, 2004 (a)

ESTEVÃO, Carlos Vilar. Justiça, direitos humanos e tendências da política educacional da actual coligação governativa em Portugal. VIII Congresso LusoAfro-Brasileiro de Ciências Sociais, Coimbra, set, 2004, 18p. Disponível: http://www.ces.uc.pt/lab2004/inscricao/pdfs/painel54/Carlos_Estevao.pdf. Acesso: 14/4/2010

. Direitos humanos e educação para uma outra democracia. Ensaio: avaliação e políticas públicas em Educação, v.19, n.70, p. 9 - 20, mar 2011.

. Educação, conflito e convivência democrática. Ensaio: avaliação e políticas públicas em Educação, v.16, n.61, p.503-513, dez 2008.

- Educação, globalizações e cosmopolitismos: novos direitos, novas desigualdades. Revista Portuguesa de Educação, v.22, n.2, p. 35-52, 2009. Disponível em: http://www.scielo.oces.mctes.pt/pdf/rpe/v22n2/v22n2a03, consultado em 07/08/2014.

IDEB. Disponível em: <http://ideb.mec.gov.br/> Acesso em: 29/09/2013.

FIGARI, Gérard. Avaliar que referencial? Porto, PT: Porto Editora, 1996.

FREITAS, Dirce Nei T.. A avaliação da educação básica no Brasil: dimensão normativa, pedagógica e educativa. Estudos em Avaliação Educacional, São Paulo, v. 20, n. 43, maio/ago. 2009.

GUBA, Egon G., LINCOLN, Yvonna S. Avaliação de quarta geração. Campinas,SP: editora da Unicamp, 2011.

HADJI, Charles. A avalição, regras do jogo: das intenções aos instrumentos. Porto, PT: Porto Editora, 1994.

JANNUZZI, Paulo. Indicadores sociais no Brasil. SP: Alínea, 2009.

Maroy Christian, Dupriez Vincent. La régulation dans les systèmes scolaires [Proposition théorique et analyse du cadre structurel en Belgique francophone]. Revue française de pédagogie, v.130, L’administration de l'éducation. p.73-87, 2000.

Maroy Christian. Regulação dos sistemas educacionais. In: ZANTEN, Agnés van (coord) Dicionário de Educação. Petrópolis, RJ: Vozes, 2011. P. 688- 693. 
MAROY, Christian; VOISIN, Annelise. As transformações recentes das políticas de accountability na educação: desafios e incidências das ferramentas de ação pública Educação \& Sociedade, v.34, n.124, p. 881-901, jul./set. 2013. Disponível em: $<$ http://www.redalyc.org/articulo.oa?id=87328534012> , acesso em 30/08/2014.

MULLER, P., SUREL, Y. A análise de políticas públicas. Pelotas: Educat, 2002.

OLIVEIRA, Romualdo Portela de; ARAUJO, Gilda Cardoso de. Qualidade do ensino: uma nova dimensão da luta pelo direito à educação. Rio de Janeiro, n. 28, p. 5-23, 2005.

PALUMBO, Dennis J; CALISTA, Donald J. Opening up the Black Box: Implementation and the Policy Process. In: Implementation and the Policy Process: Opening Up the Black Box. Greenwood Press. New York, 1990.

WERLE, Flávia Obino Corrêa (org). Avaliação em larga escala: foco na escola. São Leopoldo/Brasília: Oikos/Liberlivro, 2010. 256 p.

YANNOULAS, Silvia Cristina, SOUZA, Camila Rosa, ASSIS, Samuel. Políticas educacionais e o estado avaliador: uma relação conflitante. Sociedade em Debate, Pelotas, 15(2): 55-67, jul.-dez./2009. Disponível: http://www.google. $\mathrm{com} / \mathrm{url}$ ? sa $=\mathrm{t} \& \mathrm{rct}=\mathrm{j} \& \mathrm{q}=\&$ esrc $=\mathrm{s} \&$ source $=$ web\&cd $=1 \& \mathrm{ved}=0 \mathrm{CB} 4 \mathrm{QFjAA} \& u r \mathrm{r}$ http $\% 3 \mathrm{~A} \% 2 \mathrm{~F} \% 2 \mathrm{Fwww}$.rle.ucpel.tche.br $\% 2$ Findex.php $\% 2 \mathrm{Frsd} \% 2 \mathrm{Farticle} \% 2 \mathrm{~F}$ download $\% 2 \mathrm{~F} 351 \% 2 \mathrm{~F} 309 \&$ ei= $\mathrm{qKD}$ cVIXNIoa6ggSprIHwDg\&usg=AFQjCN HV1VoBatTtdx09w5ga7OWOKxCuPw\&sig2=p9pZ4kFu5JH0UC7A0IGKPw \&bvm=bv.85761416,d.eXY consulta 10/09/2012.

FLÁVIA OBINO CORRÊA WERLE é doutora em educação pela PUCRS, professora da Universidade do Vale do Rio dos Sinos _ UNISINOS e pesquisadora do CNPq. E-mail: flaviaw@unisinos.br

JANAINA FRANCISCATO AUDINO é doutoranda do Programa de Pós-Graduação em Educação da Unisinos, universidade em que também obteve o título de Mestre em Educação. Atua como executiva do Instituto JAMA em Porto Alegre, RS. E-mail: janainaaudino@hotmail.com 